\title{
The Influence of Hyperthyroidism and
}

\section{Hypothyroidism on the $\beta$-Adrenergic Responsiveness}

\author{
of the Turkey Erythrocyte
}

\author{
John P. Bilezikian, John N. Loeb, and Donald E. Gammon, Department of \\ Medicine, College of Physicians and Surgeons, Columbia University, \\ New York 10032
}

A B S TRACT The mechanisms responsible for altered adrenergic tone in hyperthyroidism and hypothyroidism are not fully understood. To investigate these mechanisms, the $\beta$-adrenergic receptor-cyclic AMP complex of the turkey erythrocyte was studied among groups of normal, hyperthyroid, and hypothyroid turkeys. In erythrocytes obtained from hypothyroid turkeys, there were fewer $\beta$-adrenergic receptors than in normal cells as determined by the specific binding of [125I]iodohydroxybenzylpindolol, as well as associated decreases both in catecholamine-responsive adenylate cyclase activity and in cellular cyclic AMP content. In contrast, erythrocytes obtained from hyperthyroid turkeys contained the same number of $\beta$-receptors and had the same catecholamine-responsive adenylate cyclase activity as cells from normal birds. Other characteristics of the $\beta$-receptors in cells from hyperthyroid birds were indistinguishable from those present in normal erythrocytes. However, within the range of circulating catecholamine concentrations, $5-50 \mathrm{nM}$, the erythrocytes of the hyperthyroid turkeys generated substantially more cyclic AMP after exposure to isoproterenol than did normal cells. These results suggest that thyroid hormone affects $\beta$-receptor-cyclic AMP interrelationships in the turkey erythrocyte by two distinct mechanisms: (a) In hypothyroidism, both $\beta$-receptors and catecholamine-dependent cyclic AMP formation are coordinately decreased; $(b)$ in hyperthyroidism, $\beta$-receptors are unchanged but there is an amplification of the hormonal signal so that occupation

A preliminary report of this work was presented at the 60th Annual Meeting of the Endocrine Society, Miami Beach, Fla., 14 June 1978.

Dr. Bilezikian is Molly Berns Senior Investigator of the New York Heart Association and the recipient of Research Career Development Award 5 K04 HL-00383.

Received for publication 31 July 1978 and in revised form 12 October 1978. of a given number of receptors at physiological concentrations of catecholamines leads to increased levels of cyclic AMP.

\section{INTRODUCTION}

Thyrotoxicosis is associated with cardiac, metabolic, and nervous system manifestations of increased adrenergic activity (1). The remarkable efficacy of the $\beta$ adrenergic inhibitor propranolol in alleviating the signs and symptoms of thyrotoxicosis (2) without affecting circulating thyroid hormone levels (3) has implicated a specific influence of the thyroid hormones upon $\beta$-adrenergic mechanisms of catecholamine action.

Numerous experimental models to study the biochemical bases for the apparent increase in adrenergic responsiveness in hyperthyroidism and the converse in hypothyroidism have focused upon catecholaminesensitive adenylate cyclase and phosphorylase activities as well as upon direct physiological concomitants of catecholamine actions $(4,5)$. An additional potential site of thyroid hormone influence which could mediate possible effects at these more distal points is the $\beta$ receptor itself, the putative cellular recognition site for $\beta$-adrenergic catecholamines. The development of suitable radioligands that can be used to detect specific binding sites with the characteristics of $\beta$-adrenergic receptors (6) has recently permitted an inquiry into this possibility (7-9). The purpose of the current investigation was twofold: $(a)$ to examine the hypothesis that $\beta$-adrenergic receptors may be altered in states of thyroid hormone excess and deficiency; and $(b)$ to relate data on the characteristics of $\beta$-receptors in hypothyroidism and hyperthyroidism to biochemical events that follow their occupation. The turkey erythrocyte was used as the experimental model because both its $\beta$-receptor $(10,11)$ and its physiological responses to $\beta$-adrenergic agents $(12,13)$ have already been well characterized, and because sustained hyperthyroidism 
and hypothyroidism were found to be conveniently established in the turkey.

\section{METHODS}

Maintenance of turkeys. White female turkeys weighing $12-15 \mathrm{lb}$ were obtained from The Butcher, Bronx, N. Y., banded, and kept in three separate cages. Normal turkeys were fed a well-balanced diet (Layena Complete Animal Feed, Ralston Purina Co., St. Louis, Mo.) and were provided with water ad libitum. Hyperthyroid turkeys were maintained on the same diet, except for the addition of $\mathrm{L}$-thyroxine $(3 \mu \mathrm{g} / \mathrm{ml})$ to the drinking water. Their daily intake of L-thyroxine was in the range of 600-900 $\mu \mathrm{g}$. Hypothyroidism was established in one of two ways: $(a)$ by the provision of a low-iodine diet (14) fortified with vitamins (ICN Pharmaceuticals Inc., Cleveland, Ohio) and the addition of $0.5 \%$ sodium perchlorate to to the drinking water; or $(b)$ by the intravenous administration of an ablative dose $(10 \mathrm{mCi})$ of ${ }^{131} \mathrm{I}^{-}$. When radioactivity in the serum of the latter birds was no longer detectable, they were maintained among the normal turkeys and fed an identical diet. Each of the above groups of turkeys contained three to four birds.

Preparation of plasma samples, washed erythrocytes, and erythrocyte hemolysates. Heparinized blood was obtained by syringe from a wing vein. Blood from at least three turkeys in each group was sampled in any given experiment. After centrifugation at $400 \mathrm{~g}$ for $10 \mathrm{~min}$, the plasma was removed and stored in aliquots at $-20^{\circ} \mathrm{C}$ for subsequent assays. Erythrocytes were washed by suspension in incubation buffer containing $150 \mathrm{mM} \mathrm{NaCl}, 10 \mathrm{mM} \mathrm{KCl}, 11.1 \mathrm{mM}$ glucose, and $10 \mathrm{mM}$ Tris at $\mathrm{pH} 7.4$, and were washed three times before use. For the adenylate cyclase assay, an aliquot of washed, packed erythrocytes was hemolyzed in 2 vol of buffer containing $50 \mathrm{mM}$ Tris at $\mathrm{pH} 7.5,5 \mathrm{mM} \mathrm{KCl}, 1 \mathrm{mM} \mathrm{MgSO}$, and $20 \mathrm{mM}$ dithiothreitol (11). After centrifugation at $6,400 \mathrm{~g}$ for $15 \mathrm{~min}$, the hemolyzed erythrocyte preparations were resuspended in the same buffer, centrifuged again, and finally resuspended in a volume corresponding to twice that of the original packed cells. This crude, adenylate cyclase-rich fraction was stable for at least 3 mo when stored at $-80^{\circ} \mathrm{C}$. For binding studies, and for the determination of intracellular cyclic AMP, aliquots of washed cells were suspended to their original volume in incubation buffer, maintained at $4^{\circ} \mathrm{C}$, and studied on the same day.

Adenylate cyclase assay. Adenylate cyclase activity in crude erythrocyte hemolysates was determined in a wellestablished assay that depends upon the conversion of $\left[\alpha^{32}\right.$ P]ATP (ICN Pharmaceuticals Inc.) to [ ${ }^{32}$ P]cyclic AMP (15). Data points for all experiments are the averages of triplicate determinations (coefficient of variation, 15\%). Adenylate cyclase activities of different groups of turkey erythrocytes were all measured on the same day.

Preparation of [125I]iodohydroxybenzylpindolol. $\mathrm{Hy}$ droxybenzylpindolol (HYP $)^{1}$ was iodinated according to methods previously described $(10,16)$. Before use, an aliquot of [125I]HYP was reduced to dryness under nitrogen and reconstituted in the assay buffer.

Binding assay. Freshly obtained, washed, intact turkey erythrocytes $\left(2.5 \times 10^{7} / \mathrm{ml}\right)$ and $\left.{ }^{125} \mathrm{I}\right] \mathrm{HYP}(40 \mathrm{pM}$ unless otherwise indicated) were incubated with other compounds as noted in the individual experiments. After equilibrium was reached at $37^{\circ} \mathrm{C}(30 \mathrm{~min}), 100-\mu \mathrm{l}$ samples were removed in triplicate and immediately filtered over Gelman A/E glass filters (A. H. Thomas, Philadelphia, Pa.). These filters re-

${ }^{1}$ Abbreviations used in this paper: Gpp (NH)p, guanylyl 5'imidophosphate; HYP, hydroxybenzylpindolol. tained the erythrocytes and the ligand bound to them. They were washed with $12 \mathrm{ml}$ of Tris buffer $(10 \mathrm{mM}, \mathrm{pH} 7.5)$ at room temperature, and the radioactivity retained on the filters was determined in a Packard Auto-Gamma spectrometer (Packard Instrument Co. Inc., Downers Grove, Ill.). Under these conditions the assay blank (radioactivity trapped on the filter in the absence of cells) was $150 / 15,000 \mathrm{cpm}$ filtered ( $1 \%$ ), a negligible component of the $35-50 \%$ bound to the erythrocyte suspension. The results are reported in terms of specific binding defined as that component of total binding inhibited by $0.1 \mu \mathrm{M}$ unlabeled HYP. Specific binding was generally $60 \%$ of the total binding. The coefficient of variation among triplicate determinations was $5 \%$. All experiments comparing the binding characteristics of different groups of turkey erythrocytes were performed on the same day.

Measurement of cyclic AMP. Intact, washed erythrocytes $\left(7.5 \times 10^{8} / \mathrm{ml}\right)$ were incubated at $37^{\circ} \mathrm{C}$ for $30 \mathrm{~min}$ in the presence of specific agents noted in the individual experiments, and the cells were processed according to a previously published protocol (12). Experiments comparing the amount of cyclic AMP generated by erythrocytes from different groups of turkeys were performed on the same day. Cyclic AMP was detected by radioimmunoassay according to the method of Steiner et al. (17).

Determination of catecholamines. Plasma samples were obtained from awake turkeys under the same conditions that blood was obtained for other portions of this study. The turkeys were gently held but were not otherwise restrained. Blood was immediately introduced into iced test tubes containing EGTA and glutathione and all samples assayed in quadruplicate according to the method of Passon and Peuler (18).

$\mathrm{L}-$ Thyroxine and L-triiodothyronine. L-Thyroxine and Ltriiodothyronine were measured by radioimmunoassay (19). There was no significant overlap by either specific radioimmunoassay for the other hormone. Unextracted plasma was used. The lower limit of detectability for L-thyroxine was 0.25 $\mu \mathrm{g} / \mathrm{ml}$, and, for L-triiodothyronine, $10 \mathrm{ng} / \mathrm{ml}$. Plasma samples from all turkeys drawn at a specified time were analyzed simultaneously.

Other biochemical measurements. Uric acid, total protein, globulin, total lipids, cholesterol, serum glutamic-oxaloacetic transaminase, serum glutamic-pyruvic transaminase, and lactic dehydrogenase were all determined by standard autoAnalyzer techniques (Technicon Instruments, Tarrytown, N. Y.). Creatine phosphokinase was determined by a previously published method (20).

\section{RESULTS}

\section{Establishment of the hyperthyroid and hypothyroid} states. Turkeys developed chemical hyperthyroidism within 1-2 wk and hypothyroidism within 6-8 wk after the treatment protocols were initiated (see Methods). Over an 8-mo period of observation the hyperthyroid turkeys were noted to be excitable, hyperkinetic, and apprehensive, whereas the hypothyroid birds were generally docile and much less active. In addition, the hyperthyroid birds showed conspicuous signs of heat intolerance, including panting and standing with their feet in water, whereas hypothyroid turkeys often shivered and warmed their heads under their wings. Basal body temperature was significantly $(P<0.002)$ elevated in hyperthyroid turkeys $\left(41.0 \pm 0.12^{\circ} \mathrm{C}\right)$ and decreased in hypothyroid turkeys $\left(39.8 \pm 0.10^{\circ} \mathrm{C}\right)$ as compared with that of normal birds $\left(40.5 \pm 0.06^{\circ} \mathrm{C}\right)$. The rest- 
ing heart rate was higher in the hyperthyroid ( $262 \pm 18$ / min) than in the euthyroid birds $(217 \pm 19 / \mathrm{min})$. These clinical observations were confirmed by measuring the circulating concentration of L-thyroxine, which was $10.0 \pm 1.4 \mu \mathrm{g} / \mathrm{dl}$ in the hyperthyroid birds and $0.34 \pm 0.04$ $\mu \mathrm{g} / \mathrm{dl}$ in the hypothyroid birds - both significantly $(P<0.05)$ different from normal $(0.57 \pm 0.08 \mu \mathrm{g} / \mathrm{dl})$. The "low" thyroxine level in the normal turkey-relative to the level in human subjects - reflects the absence of specific thyroid hormone-binding proteins in avian species (21). The circulating L-triiodothyronine concentration in the hypothyroid birds $(22 \mathrm{ng} / \mathrm{ml})$ was also significantly lower than normal $(111 \pm 20 \mathrm{ng} / \mathrm{ml} ; P$ $<0.05$ ). It has been previously reported in certain mammals that the levels of circulating catecholamines are influenced by thyroid hormone (22); among these groups of turkeys, however, the total circulating catecholamine levels did not significantly differ (range: $14 \pm 4$ to $23 \pm 6 \mathrm{nM}$ ). Hyperthyroidism was associated with other departures from normal as indicated by lower serum concentrations of uric acid, total lipids, globulins, and cholesterol. In hypothyroid turkeys, concentrations of the following serum components were above the normal range: cholesterol, uric acid, serum glutamic-pyruvic transaminase, serum glutamic-oxaloacetic transaminase, lactic dehydrogenase, and creatine phosphokinase. These observations were repeatedly and reproducibly made over the 8 to 10 -mo period of study.

Binding of $\left[{ }^{125} I\right] H Y P$ to intact turkey erythrocytes. Intact erythrocytes from hypothyroid, normal, and hyperthyroid turkeys demonstrated specific binding of the radioligand $\left[{ }^{125} \mathrm{I}\right] \mathrm{HYP}$. In eight separate experiments in which erythrocytes from individual turkeys were studied separately at a ligand concentration of 40 $\mathrm{pM}$, the average specific binding of [ $\left.{ }^{125} \mathrm{I}\right] \mathrm{HYP}$ by hyperthyroid turkey erythrocytes $\left(2.95 \pm 0.33 \mathrm{fmol} / 10^{7}\right.$ cells $)$ was not significantly different from the binding observed in euthyroid turkey erythrocytes $(2.74 \pm 0.39$ fmol/10 $10^{7}$ cells). In contrast, hypothyroid turkey erythrocytes bound significantly less [ $\left.{ }^{125} \mathrm{I}\right] \mathrm{HYP}(2.26 \pm 0.23$ fmol/107 cells) than did cells from normals $(P<0.05)$. The same decrease in erythrocyte binding capacity was noted for the radiothyroidectomized turkeys as for the turkeys in which hypothyroidism had instead been induced by diet. This reduction in ligand binding was furthermore observed at free concentrations of [ $\left.{ }^{125} \mathrm{I}\right]$ $\mathrm{HYP}$ as low as $10 \mathrm{pM}$. Inasmuch as the mean corpuscular volume for erythrocytes in all groups was similar $\left(140 \pm 4 \mu \mathrm{m}^{3}\right)$, the observed differences in ligand binding could not be ascribed to differences in membrane surface area per cell but instead reflected differences in membrane receptor density. Binding in each case was saturable. Half-maximal occupation of specific binding sites occurred at approximately $40 \mathrm{pM}$ for all three groups (Fig. 1). By Scatchard analysis (23) the

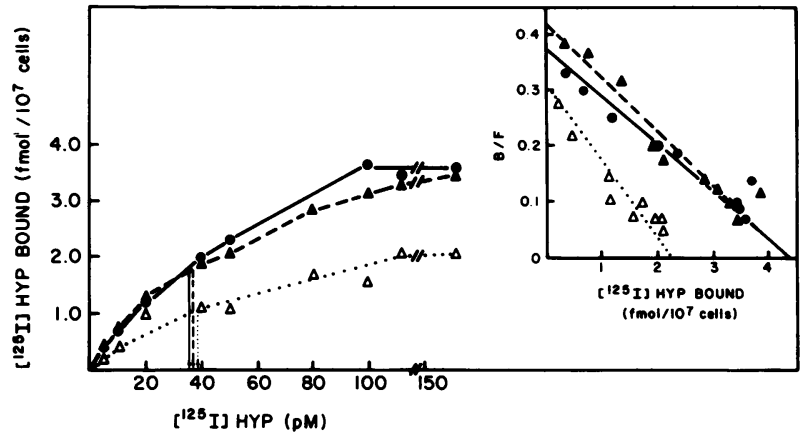

FIGURE 1 Saturation of $\beta$-receptor sites in erythrocytes from normal, hyperthyroid, and hypothyroid turkeys as a function of radioligand concentration. Turkey erythrocytes $\left(3 \times 10^{7} / \mathrm{ml}\right)$ were incubated with increasing concentrations of [ $\left.{ }^{125} \mathrm{I}\right] \mathrm{HYP}$ as noted on the ordinate. Binding was determined as described in Methods. For every concentration of ligand, nonspecific binding was determined by the amount of radioactivity bound in the presence of $0.1 \mu \mathrm{M}$ unlabeled HYP. This value was subtracted from the total binding at that concentration of ligand, resulting in the amount of $\left[{ }^{125} \mathrm{I}\right] \mathrm{HYP}$ specifically bound which is depicted in the figure. The data shown are representative of four separate experiments. Individual data points are the means of triplicate determinations. (Inset) The data

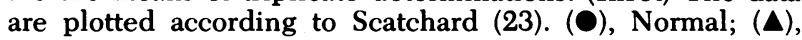
hyperthyroid; $(\triangle)$, hypothyroid.

binding capacity of the hypothyroid turkey erythrocytes was half that of normal (Fig. 1, inset). The slope of the line for the hypothyroid birds was not significantly different from the slopes for normal or hyperthyroid turkeys. Association kinetics were rapid, with halfmaximal binding being established within 5 min at $37^{\circ} \mathrm{C}$ for all groups (data not shown). Binding was also reversible, with similar dissociation rate constants $\left(k_{-1}\right)$ in the range of 0.034 to $0.047 / \mathrm{min}$ for all three groups (Fig. 2). Dissociation of bound ligand occurred at the same rate and to the same extent whether excess unlabeled HYP or dilution alone was used to dissociate [ $\left.{ }^{125} \mathrm{I}\right] \mathrm{HYP}$ from the receptor. These observations suggest that negatively cooperative interactions between receptor sites did not occur in any of the groups studied. The concentration at which the $\beta$-adrenergic agonist isoproterenol was able to inhibit binding of [125I]HYP half-maximally was similar among the three groups (Fig. 3). Prior exposure of turkey erythrocytes to isoproterenol did not alter the number of detectable binding sites, nor did it change their affinity for $\beta$-adrenergic agonists (data not shown). Guanylyl 5'imidophosphate $[\mathrm{Gpp}(\mathrm{NH}) \mathrm{p}]$ did not alter the binding affinity for (-)-isoproterenol. Strict stereospecificity for $(-)$-antipodes of $\boldsymbol{\beta}$-adrenergic agonists and antagonists was observed in each case. The salient feature in these binding studies, therefore, was a decrease in the number of $\beta$-receptors in the hypothyroid turkey erythrocyte. In all other respects, the characteristics of the $\beta$-receptor in the hypothyroid erythrocyte were indis- 


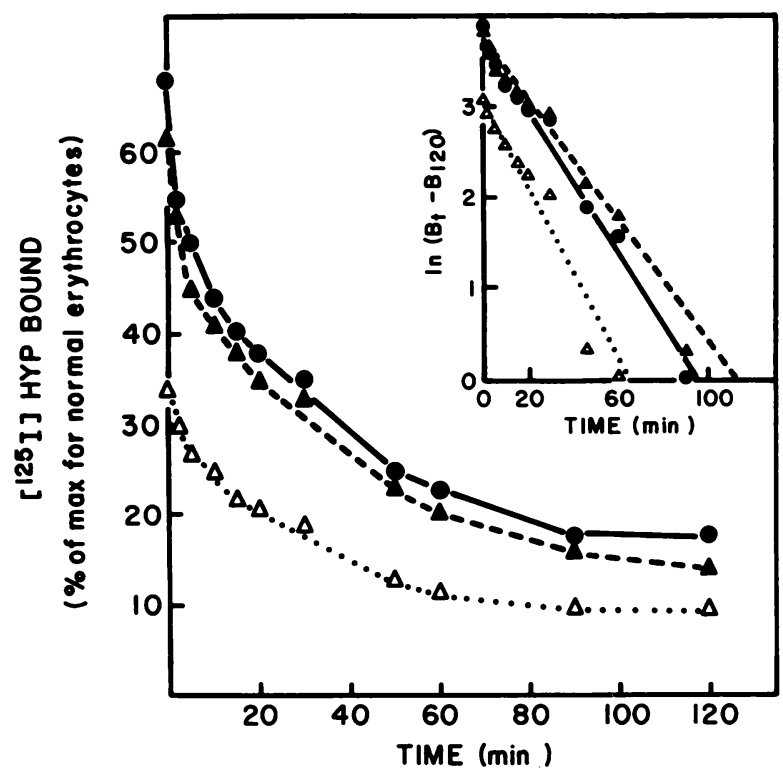

FIGURE 2 Dissociation of $\left.{ }^{125} \mathrm{I}\right]$ HYP from the $\beta$-receptor of hyperthyroid, normal, and hypothyroid turkey erythrocytes. Freshly obtained turkey erythrocytes were washed and resuspended $\left(3 \times 10^{7} / \mathrm{ml}\right)$ in incubation buffer containing $40 \mathrm{pM}$ [125] HYP at $25^{\circ} \mathrm{C}$. After $60 \mathrm{~min}$, the cells were immediately chilled, centrifuged at $3,000 \mathrm{~g}$ and washed three times in cold incubation medium. The cells were resuspended in a 100 -fold volume excess of incubation medium, and 10-ml aliquots were filtered in duplicate at the times indicated. The data are represented as the percent of $\left[{ }^{125} \mathrm{I}\right] \mathrm{HYP}$ specifically bound to normal erythrocytes at equilibrium, or, inset, as the natural logarithm ( $(\mathrm{n})$ of the difference between binding at equilibrium and binding at $t=120 \mathrm{~min}$. (O), Normal; $(\Delta)$, hyperthyroid; $(\Delta)$, hypothyroid. The lines were determined by linear regression analysis.

tinguishable from normal. On the other hand, the $\beta$ receptor of the hyperthyroid turkey erythrocyte was identical in all respects to normal, including receptor number.

Adenylate cyclase activity. Basal adenylate cyclase activity was found to be similar in crude hemolysates of hyperthyroid and euthyroid erythrocytes, but it was significantly lower in hypothyroid cells (Table I). In no group was basal activity decreased by the $\beta$-adrenergic inhibitor propranolol, suggesting that under these experimental conditions basal adenylate cyclase activity cannot be attributed to adrenergic effects. (-)-Isoproterenol by itself caused a significant four- to sixfold stimulation above basal levels in all groups. The (-)-isoproterenol-stimulated activity, in contrast to basal activity, was completely inhibited by propranolol but was not affected by the $\alpha$-adrenergic inhibitor phentolamine. Although hypothyroid turkey erythrocytes showed the same relative stimulation over their basal level, the absolute activity of isoproterenol-sensitive adenylate cyclase was significantly lower than in the normal cells. $\mathrm{Gpp}(\mathrm{NH}) \mathrm{p}$ caused a significant

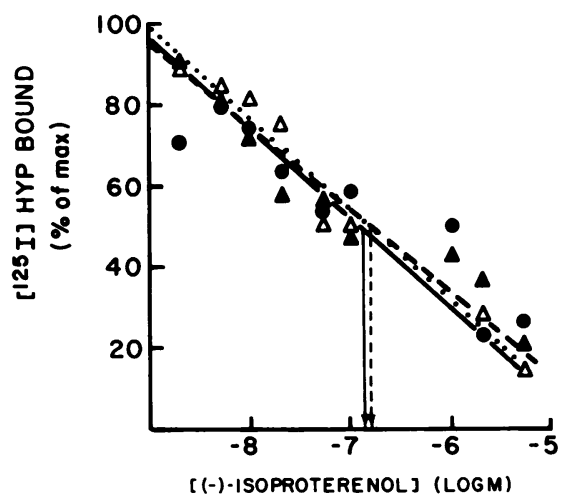

FIgURE 3 Inhibition of [ $\left.{ }^{125} \mathrm{I}\right] \mathrm{HYP}$ binding by (-)-isoproterenol. Hyperthyroid $(\Delta)$, normal $(\bullet)$, and hypothyroid $(\Delta)$ turkey erythrocytes were incubated with $40 \mathrm{pM}\left[{ }^{125} \mathrm{I}\right] \mathrm{HYP}$ and increasing concentrations of (-)-isoproterenol. Specific binding was determined as described in Methods.

stimulation of basal adenylate cyclase and together with isoproterenol was responsible for a synergistic increase in isoproterenol-responsive adenylate cyclase activity. Addition of $\mathrm{Gpp}(\mathrm{NH}) \mathrm{p}$ did not, however, affect the comparative observations made in the presence of isoproterenol alone, namely, that hyperthyroid and euthyroid hemolysates had similar maximal-stimulatable adenylate cyclase activity, whereas hypothyroid erythrocytes had significantly less. The component of adenylate cyclase activity responsive to fluoride was also decreased in the hypothyroid state (Table I). Increasing concentrations of (-)-isoproterenol were accompanied by increased adenylate cyclase activity, with half-maximal activation occurring at $\cong 2-4 \mu \mathrm{M}$ for each group (Fig. 4A). Similarly, half-maximal inhibition of isoproterenol-responsive activity by (-)-propranolol

TABLE I

Adenylate Cyclase Activity in Hemolysates from Hyperthyroid, Normal, and Hypothyroid Turkey Erythrocytes

\begin{tabular}{lccc}
\hline & Hyperthyroid & Normal & Hypothyroid \\
\hline Basal & $9.9 \pm 1.6$ & $10.5 \pm 2.2$ & $4.9 \pm 1.6^{*}$ \\
$\begin{array}{l}\text { Gpp }(\mathrm{NH}) \mathrm{p}, \\
\quad 70 \mu M\end{array}$ & $36.4 \pm 7.9$ & $38.5 \pm 5.1$ & $24.5 \pm 5.4^{*}$ \\
$\begin{array}{l}\text { Isoproterenol, } \\
\quad 0.5 \mathrm{mM}\end{array}$ & $51.9 \pm 5.6$ & $45.4 \pm 5.7$ & $29.4 \pm 5.1^{*}$ \\
$\quad \begin{array}{l}\text { Isoproterenol } \\
\quad+\text { Gpp(NH)p }\end{array}$ & $136 \pm 19$ & $132 \pm 14$ & $81.7 \pm 12.3^{*}$ \\
Fluoride, $8 \mathrm{mM}$ & $156 \pm 19$ & $152 \pm 19$ & $115 \pm 22^{*}$ \\
\hline
\end{tabular}

Adenylate cyclase activity was determined according to Methods. The values are expressed as picomoles of cyclic AMP generated per $10^{9}$ cell equivalents per 10 min (means $\pm \mathrm{SEM}$ ). No significant differences were observed between normal and hyperthyroid erythrocyte hemolysates $(P>0.05)$. * $P<0.01$. 
occurred at the same concentration for each group (Fig. 4B). In the hypothyroid turkey erythrocyte the magnitude of the decrease in catecholamine-sensitive adenylate cyclase activity was similar to the degree by which $\beta$-receptor sites were decreased.

Cyclic AMP content. Dose-response relationships to $\beta$-adrenergic catecholamines derived from particulate broken-cell preparations generally exhibit less sensitivity than do those examined in intact cells using either cyclic AMP generation or physiological events as markers (24). It therefore was of importance to measure the response of intact erythrocytes to isoproterenol at concentrations of catecholamines comparable to the circulating levels determined in the course of this study. Accordingly, intracellular cyclic AMP was determined after exposure to very low concentrations of (-)-isoproterenol (5-50 $\mathrm{nM})$. As shown in Fig. 5, at these low concentrations of isoproterenol, hyperthyroid turkey erythrocytes - in marked contrast to their behavior at higher concentrations - accumulated substantially more cyclic AMP than did normal erythrocytes. At concentrations $>50 \mathrm{nM}$, however, the augmented activity in the hyperthyroid erythrocytes decreased so that, at maximal concentrations of isoproterenol, the cyclic AMP concentration in hyperthyroid and normal erythrocytes was similar. In contrast, in the hypothy-

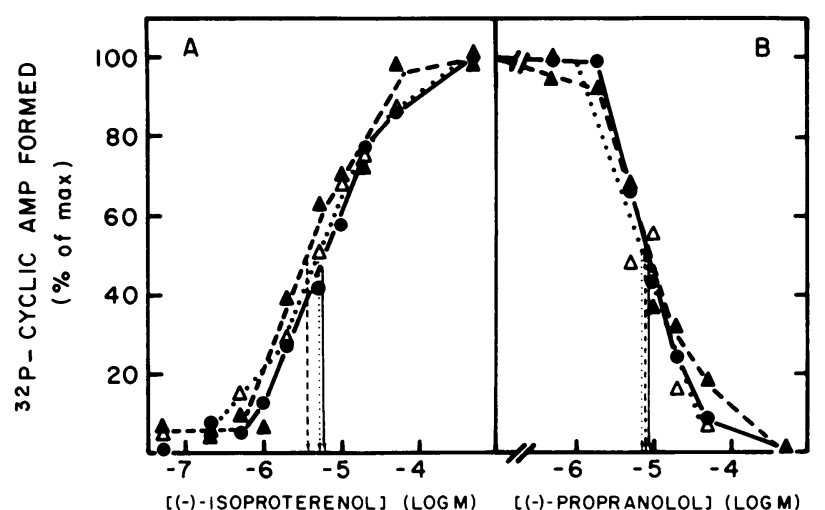

Figure 4 Stimulation and inhibition of catecholamine-sensitive adenylate cyclase in erythrocytes from hyperthyroid, normal, and hypothyroid turkeys. (A) Adenylate cyclase activity in crude hemolysates prepared from hyperthyroid $(\boldsymbol{\Delta})$, normal $(\bullet)$, or hypothyroid $(\Delta)$ turkey erythrocytes was measured in response to increasing concentrations of $(-)$-isoproterenol. The data are expressed as a percentage of maximal stimulatable adenylate cyclase for each of the groups: hyperthyroid erythrocytes $\left(44 \pm 7 \mathrm{pmol} / 10^{9}\right.$ cell equivalents); normal $(38 \pm 6)$ or hypothyroid $(26 \pm 6)$. The arrows depict half-maximal stimulation. (B) Hyperthyroid, normal, or hypothyroid erythrocyte hemolysates were exposed to (-)-isoproterenol (50 $\mu \mathrm{M})$ and increasing concentrations of (-)-propranolol. The results are expressed as a percentage of maximal activity. Arrows depict half-maximal inhibition. Both panels show the results of representative experiments performed on four separate occasions. All data points are the means of triplicate determinations.

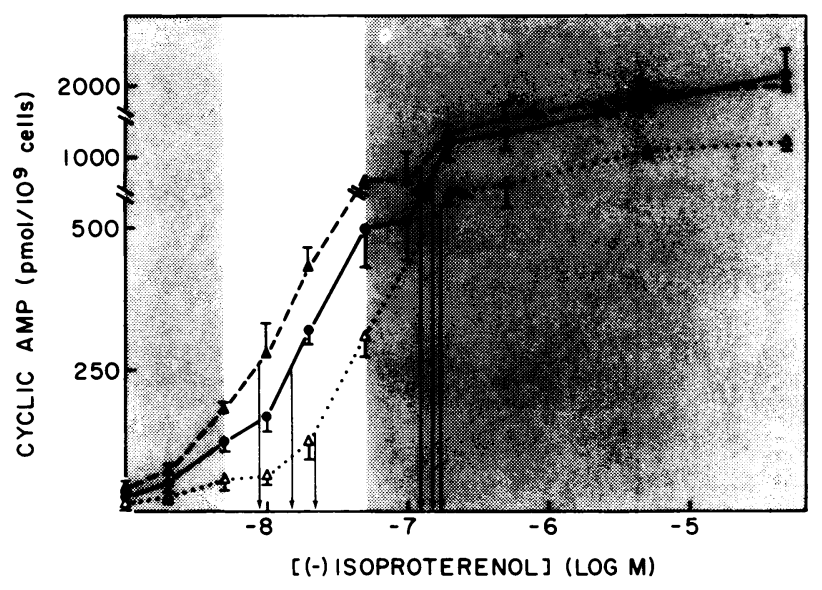

Figure 5 Accumulation of cyclic AMP in the erythrocytes of hyperthyroid, normal, and hypothyroid turkeys as a function of isoproterenol concentration. Erythrocytes were exposed to increasing concentrations of isoproterenol, and cyclic AMP was determined as described in Methods. The data represent the means \pm 1 SEM from three separate experiments in which the three groups of turkey erythrocytes were each studied in the same experiments. Arrows in the gray area of the curve represent the concentrations of isoproterenol required for halfmaximal accumulation of cyclic AMP along the entire range of isoproterenol concentrations employed. The arrows in the white area of the curve represent the concentrations of isoproterenol required for half-maximal accumulation of cyclic AMP within the physiological range of catecholamine concentrations as shown in the white area. Hyperthyroid $(\boldsymbol{\Delta})$, normal $(\bullet)$, and hypothyroid $(\triangle)$.

roid turkey erythrocyte cellular cyclic AMP was lower at both the "physiological" and "pharmacological" ends of the dose-response curve. Conventional determination of the isoproterenol concentration required for half-maximal accumulation of cyclic AMP yielded values of approximately $0.15 \mu \mathrm{M}$ for all three groups (arrows in the gray area of Fig. 5). The similarity of these values despite the apparent major differences in sensitivities to isoproterenol at the lower end of the dose-response relationship is the result of the observation that $75 \%$ of the ultimate cyclic AMP generated occurs in response to unphysiologically high concentrations of $(-)$-isoproterenol $(>50 \mathrm{nM})$. The relative catecholamine sensitivities of these three groups of erythrocytes are hence better appreciated by determining the concentration of isoproterenol required for $25 \%$ maximal stimulation, resulting in amounts of cyclic AMP generated at the physiological end of the dose-response curve. These concentrations are $0.9,15$, and $32 \mathrm{nM}$ for hyperthyroid, normal, and hypothyroid turkey erythrocytes, respectively (arrows in white area of Fig. 5). The hemolysates had negligible phosphodiesterase activity when measured directly, and similar observations were also made when experiments were carried out in the presence of the phosphodiesterase inhibitor theophylline (data not shown). 
It would thus appear that these differences are not to be accounted for by differences in cellular phosphodiesterase activity. Propranolol was found to prevent the isoproterenol-sensitive accumulation of cyclic AMP in all three groups with equal potency (Fig. 6).

\section{DISCUSSION}

The avian erythrocyte provides an opportunity to study the biochemical basis for thyroid hormone-induced changes in catecholamine sensitivity affecting a number of well-defined physiological responses to $\beta$-adrenergic agents. Many of the clinical and biochemical features of altered thyroid function generally observed in human subjects were found to be present in the turkey, and it is also noteworthy that the chronic nature of this model-as opposed to the acute, more short-term studies undertaken in previous investigations - is analogous to what is observed in disorders of human thyroid function.

The erythrocyte of the normal turkey contains a class of binding sites with extremely high affinity for the radiolabeled $\beta$-adrenergic inhibitor $\left[{ }^{125} \mathrm{I}\right] \mathrm{HYP}(10)$. The stereospecificity, saturability, and reversibility of binding, as well as the order of interaction of these sites with $\beta$-agonists and antagonists all conform to those characteristics expected for a $\beta$-adrenergic receptor. Occupation of these $\beta$-receptor sites by agonists and antagonists is functionally linked to the activation or inhibition of catecholamine-sensitive adenylate cyclase and to subsequent effects on cellular cyclic AMP levels.

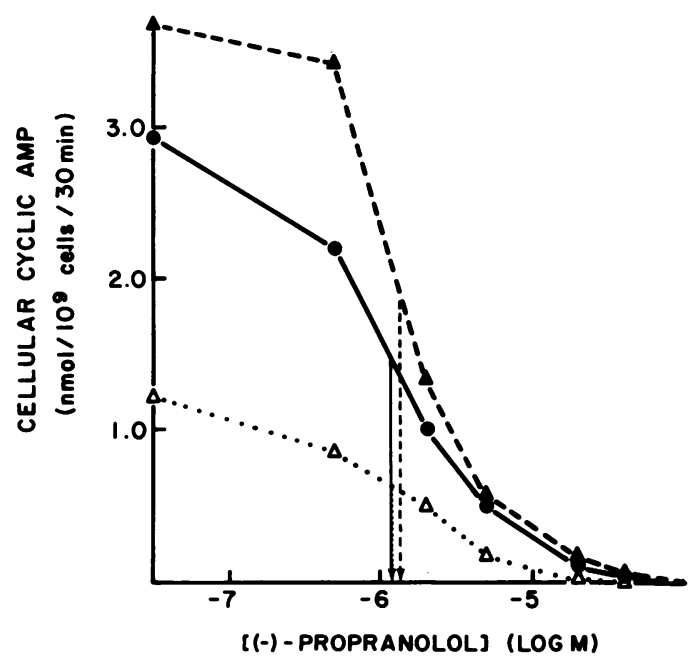

FIGURE 6 Inhibition of isoproterenol-sensitive cyclic AMP accumulation by $(-)$-propranolol. Hyperthyroid $(\boldsymbol{\Delta})$, normal $(\odot)$, or hypothyroid $(\triangle)$ turkey erythrocytes were exposed to $50 \mu \mathrm{M}(-)$-isoproterenol and increasing concentrations of (-)-propranolol. Cyclic AMP was determined as described in Methods. Arrows denote the concentrations of (-)-propranolol required for half-maximal inhibition.
The presence of these characteristics has made it possible to examine the hypothesis that thyroid hormone may influence the response of the turkey erythrocyte at the $\beta$-receptor itself or at more distal biochemical sites within the cell.

One possibility is that the observed thyroid hormonespecific effects on the $\beta$-adrenergic system are attributable to changes at the level of the $\beta$-receptor itself, the initial site of catecholamine action. Such an influence has been demonstrated in the acutely thyrotoxic rat heart, in which $\beta$-receptors have been shown to be increased in number but otherwise indistinguishable from those identified in the euthyroid rat heart $(7,8)$. Although changes in $\beta$-receptor number are sometimes associated with concomitant changes in receptormediated functions (25-27), it remains to be established that the increase in $\beta$-receptors observed in these thyrotoxic models is linked to changes in catecholamine-related biochemical or physiological properties. This question assumes greater importance in light of earlier reports suggesting that the catecholamine-sensitive adenylate cyclase activities of normal and hyperthyroid rat hearts are similar $(28,29)$. Furthermore, the $\beta$-receptor-adenylate cyclase complex has been found to be dissociated in some systems with the result that $\beta$-receptors do not always reflect changes in receptor-mediated cellular properties (30-32).

When examined in other models of hyperthyroidism, an increase in the number of $\beta$-receptors has not been consistently observed. For example, thyrotoxic rat skeletal muscle and fat cells, as well as human lymphocytes from thyrotoxic subjects, all contain $\beta$-receptors which appear to be identical in number and affinity to their normal counterparts $(8,33,34)$. Similarly, in the studies reported here, the $\beta$-receptor in the turkey erythrocyte was found to be unaffected by the hyperthyroid state. Maximal binding capacity, association and dissociation kinetics, and binding affinity were indistinguishable in normal and hyperthyroid turkeys. Agonists were able to compete with [ ${ }^{125}$ I] HYP for binding sites in erythrocytes from either normal or toxic birds equally well. There were no $\mathrm{Gpp}(\mathrm{NH})$ p-dependent shifts in agonistspecific interactions, nor was there negative or positive cooperativity among the binding sites of hyperthyroid or normal erythrocytes. The number of $\beta$-receptors could not be reduced by subsensitization after exposure to isoproterenol in either group.

Athough detailed studies of adenylate cyclase activity of the turkey erythrocyte demonstrated no significant differences between thyrotoxic and normal erythrocytes, it was necessary to interpret these findings with regard to the limitations of the adenylate cyclase assay, which requires broken-cell preparations in which hormone sensitivity may be diminished (24). This is particularly pertinent for the turkey erythrocyte, in which the sensitivity of adenylate cyclase to isopro- 
terenol does not correlate well with the much lower concentrations associated with both cyclic AMP accumulation and the stimulation of ion transport in the intact cell $(12,35)$. Because, for this reason, adenylate cyclase activity per se could not be used to answer questions related to the responsiveness of the turkey erythrocyte at concentrations of catecholamines within the physiological range, cyclic AMP itself was measured in intact cells after exposure to very low levels of isoproterenol. At concentrations of only 5-50 nM it was found that hyperthyroid turkey erythrocytes in fact generated substantially more cyclic AMP than did normal cells. Thus, despite no change in number or affinity of $\beta$-receptors, there was a significant amplification of the adrenergic signal in cells of the hyperthyroid birds. A similar set of observations has very recently been made in the hyperthyroid rat adipocyte, in which it has been shown that catecholamine-induced lipolysis is greater than normal despite the absence of changes in $\beta$-receptor number (9). Whether or not the amplified cyclic AMP responsiveness to catecholamines in the hyperthyroid turkey erythrocyte is associated with a comparable augmentation of a physiological response, such as catecholamine-dependent sodium transport, is currently under investigation. In any event, it would appear that one mechanism by which thyroid hormone may affect $\beta$-adrenergic events is by amplification of the hormonal signal at points distal to the initial cellular recognition site for catecholamines.

The capacity of many cells, including the turkey erythrocyte, to respond to maximal concentrations of a hormone with maximal cyclic AMP generation far exceeds the amount of cyclic AMP required to induce a maximal physiological response $(12,24,35)$. It is therefore probably of little physiological relevance that the difference in cyclic AMP formation between normal and hyperthyroid turkey erythrocytes is lost when pharmacological levels of isoproterenol are employed. These results underscore the importance of studying mechanisms of hormone-dependent events at concentrations of hormone within the physiological range.

In hypothyroidism - as in hyperthyroidism - the results suggest that a change in thyroid hormone level affects the actions of catecholamines. In contrast to hyperthyroidism, however, the means by which adrenergic responsiveness is altered in hypothyroidism appears, at least in part, to involve changes in $\beta$-adrenergic receptor number. Hypothyroid turkey erythrocytes demonstrated a coordinate decline in ligand binding, in isoproterenol-dependent adenylate cyclase activity, and in the generation of cyclic AMP. The degree to which all of these decreases were observed was similar. Although changes in guanyl nucleotide regulatory sites leading to altered coupling between $\beta$-receptors and adenylate cyclase could account for some (though not all) of these observations, it is not yet possible to address this question directly.

Except for the number of specific $\beta$-receptor sites, binding characteristics of the hypothyroid turkey erythrocyte were indistinguishable from those of normal and hyperthyroid cells. It is noteworthy that the increase in cyclic AMP at very low concentrations of isoproterenol was reduced in hypothyroid cells, and hence that, in the physiological range of catecholamine concentrations, major differences in cyclic AMP responsiveness were observed between all three groups of erythrocytes. Three recent studies have reported decreased cardiac and skeletal muscle $\beta$-receptors in hypothyroidism, but no further catecholamine-dependent parameters were explored $(7,36,37)$. Previous investigations, antedating the development of $\beta$-receptor-specific ligands now available, have, however, shown a decrease in catecholamine-sensitive adenylate cyclase and associated physiological events in hypothyroid target tissues (38-40). These results suggest that one mechanism for decreased adrenergic responsiveness in hypothyroidism common to many systems may be a reduction in the number of $\beta$-receptors. It is also possible that decreased adrenergic responsiveness in hypothyroidism occurs by additional mechanisms involving modulation of events beyond the $\beta$ receptor. In short-term studies of the hypothyroid fat cell, for example, catecholamine-dependent lipolysis has been found to be diminished without any apparent decrease in $\beta$-receptor number (9).

The point in the avian erythrocyte's history at which changes in thyroid hormone level induce the changes in $\beta$-adrenergic responsiveness reported here is not known. Current evidence indicates that the mature avian erythrocyte, despite the presence of a nucleus, engages in negligible RNA and protein synthesis (41). In this regard the observed changes in $\beta$-adrenergic receptor characteristics most probably reflect modifications induced during the course of erythropoiesis itself, or, less likely, subsequent changes in the mature erythrocyte induced under the influence of either insufficient or excessive hormone. The latter changes, however, would have to occur by a means independent of transcriptional mechanisms currently believed to mediate most if not all of the known effects of the thyroid hormones. Differences in $\beta$-adrenergic responsiveness were observed to be fully established within $6 \mathrm{wk}$ of the onset of the hypothyroid or hyperthyroid state, a time interval comparable to the known lifespan of avian erythrocytes (30-45 d [42]) and hence also consistent with the time necessary for the establishment of a pure population of cells produced under conditions of either insufficient or excessive thyroid hormone.

These studies have not established and indeed do not imply that the marked changes in catecholamine 
action in hyperthyroid and hypothyroid turkey erythrocytes are necessarily linked to changes in catecholamine-dependent ion transport or to other cyclic AMPdependent physiological events. Additional studies are required to explore this possibility. Nevertheless, it is clear in this experimental model that hyperthyroidism is associated with increased levels of catecholamine-dependent cyclic AMP, and that in hypothyroidism catecholamine-dependent cyclic AMP is decreased. The decreased levels of the cyclic nucleotide in hypothyroidism appear to be mediated at least in part by a reduction in $\beta$-adrenergic receptor number, whereas the increased levels in hyperthyroidism appear to occur by a process distal to the $\beta$-receptor itself. Further studies of these two mechanisms by which alterations in thyroid function can modify physiological adrenergic events may be of relevance to other target tissues, including those involved in disorders of human thyroid function as well.

\section{ACKNOWLEDGMENTS}

We thank Dr. Qais Al-Awqati for helpful suggestions.

This work was supported in part by grants HL-20859 and HD-05506 from the National Institutes of Health.

\section{REFERENCES}

1. Werner, S. C. 1978. Hyperthyroidism. In The Thyroid. S. C. Werner and S. H. Ingbar, editors. Harper \& Row, Publishers, New York. 4th edition. 591-603.

2. Irvine, W. J., and A. D. Toft. 1976. The diagnosis and treatment of thyrotoxicosis. Clin. Endocrinol. 5: 687-707.

3. Spaulding, S. W., and R. H. Noth. 1975. Thyroidcatecholamine interactions. Med. Clin. N. America. 59: 1123-1131.

4. Levey, G. S. 1971 Catecholamine sensitivity, thyroid hormone and the heart. Am. J. Med. 50: 413-420.

5. Jones, J. K., F. Ismail-Beigi, and I. S. Edelman. 1972 Rat liver adenyl cyclase activity in various thyroid states. J. Clin. Invest. 51: 2498-2501.

6. Maguire, M. E., E. M. Ross, and A. G. Gilman. 1977. $\beta$-Adrenergic receptor: Ligand binding properties and the interaction with adenyl cyclase. Adv. Cyclic Nucleotide Res. 8: 1-83.

7. Ciraldi, T., and G. V. Marinetti. 1977. Thyroxine and propylthiouracil effects in vivo on alpha and beta adrenergic receptors in the heart. Biochem. Biophys. Res. Commun. 74: 984-991.

8. Williams, L. T., R. J. Lefkowitz, A. M. Watanabe, D. R Hathaway, and H. R. Besch, Jr. 1977. Thyroid hormone regulation of $\beta$-adrenergic receptor number.J. Biol Chem. 252: 2787-2789.

9. Malban, C. C., F. J. Morano, R. J. Cabelli, and J. N. Fain. 1978. Fat cell adenylate cyclase and $\beta$-adrenergic receptors in altered thyroid states. J. Biol. Chem. 253: 671-678.

10. Brown, E. M., D. Hauser, F. Troxler, and G. D. Aurbach. 1976. $\beta$-Adrenergic receptor interactions: Characterization of iodohydroxybenzylpindolol as a specific ligand. J. Biol. Chem. 251: 1232-1238.

11. Bilezikian, J. P. 1976. The interrelationship between $\beta$ adrenergic receptors and adenylate cyclase activity in the turkey erythrocyte. In Modern Pharmacology. Gerald S. Levy, editor. Marcel Dekker, Inc., New York. 349-371.

12. Gardner, J. D., H. L. Klaeveman, J. P. Bilezikian, and G. D. Aurbach. 1974. Stimulation of sodium transport in turkey erythrocytes by cyclic 3', 5'-AMP. Endocrinology. 95: 499-507.

13. Rudolph, S. A., D. E. Schafer, and P. Greengard. 1977. Effects of cholera enterotoxin on catecholamine-stimulated changes in cation fluxes, cell volume, and cyclic AMP levels in the turkey erythrocyte. J. Biol. Chem. 252: 7132-7139.

14. Remington, R. E. 1937. Improved growth in rats on iodine-deficient diets. J. Nutr. 13: 223-233.

15. Salomon, Y., C. Londos, and M. Rodbell. 1974. A highly sensitive adenylate cyclase assay. Anal. Biochem. 58: 541-548.

16. Maguire, M. E., R. A. Wiklund, H. J. Anderson, and A. G. Gilman. 1976. Binding of $\left[{ }^{125} I\right]$ iodohydroxybenzylpindolol to putative $\beta$-adrenergic receptors of rat glioma cells and other cell clones. J. Biol. Chem. 251: 1221-1231.

17. Steiner, A. L., C. W. Parker, and D. M. Kipnis. 1972. Radioimmunoassay for cyclic nucleotides. I. Preparation of antibodies and iodinated cyclic nucleotides. J. Biol. Chem. 247: 1106-1113.

18. Passon, P. G., and J. D. Peuler, 1973. A simplified radiometric assay for plasma norepinephrine and epinephrine. Anal. Biochem. 51: 618-631.

19. Hollander, C. S., and L. Shenkman. 1974. Radioimmunoassays triiodothyronine and thyroxine. In Nuclear Medicine In Vitro. B. Rothfeld, editor. J. B. Lippincott Co., Philadelphia. 136-149.

20. Rosalki, S. B., 1967. An improved procedure for serum creatine phosphokinase determination. J. Lab. Clin. Med. 69: 696-705.

21. Ringer, R. K., 1976. Thyroids. In Avian Physiology. P. D. Sturkie, editor. Springer-Verlag New York Inc., New York. $348-358$.

22. Stoffer, S. S., N. Jiang, C. A. Gorman, and G. M. Pikler. 1973. Plasma catecholamines in hypothyroidism and hyperthyroidism. J. Clin. Endocrinol. Metab. 36: 587589.

23. Scatchard, G. 1949. The attractions of proteins for small molecules and ions. Ann. N. Y. Acad. Sci. 51: 660-672.

24. Robison, G. A., R. W. Butcher, and E. W. Sutherland. 1968. Cyclic AMP. Ann. Rev. Biochem. 31: 149-173.

25. Kebabian, J. W., M. Zatz, J. A. Romero, and J. Axelrod. 1975. Rapid changes in rat pineal $\beta$-adrenergic receptor: Alterations in $l-\left[{ }^{3} \mathrm{H}\right]$ alprenolol binding and adenylate cyclase. Proc. Natl. Acad. Aci. U. S. A. 72: 3734-3739.

26. Wolfe, B. B., T. K. Harden, and P. B. Molinoff. 1976. $\beta$-Adrenergic receptors in rat liver: Effects of adrenalectomy. Proc. Natl. Acad. Sci. U. S. A. 73: 1343-1347.

27. Mickey, J., R. Tate, and R. J. Lefkowitz. 1975. Subsensitivity of adenylate cyclase and decreased $\beta$-adrenergic receptor binding after chronic exposure to (-)-isoproterenol in vitro. J. Biol. Chem. 250: 5727-5729.

28. Levey, G. S., C. L. Skelton, and S. E. Epstein. 1969. Influence of hyperthyroidism on the effect of norepinephrine on myocardial adenyl cyclase activity and contractile state. Endocrinology. 85: 1004-1009.

29. McNeil, J. H., L. D. Muschek, and T. M. Brody. 1969. The effect of triiodothyronine on cyclic AMP, phosphorylase, and adenyl cyclase in the rat heart. Can. J. Physiol. Pharmacol. 47: 913-916.

30. Maguire, M. E., L. L. Brunton, R. A. Wiklund, H. J. Anderson, P. M. VanArsdale, and A. G. Gilman. 1976. Hormone receptors and the control of cyclic AMP metab- 
olism in parental and hybrid somatic cells. Recent Prog. Horm. Res. 33: 633-667.

31. Charness, M. E., D. B. Bylund, B. S. Beckman, M. D. Hollenberg, and S. H. Snyder. 1976. Independent variation of $\beta$-adrenergic receptor binding and catecholaminestimulated adenylate cyclase activity in rat erythrocytes. Life Sci. 19: 243-250.

32. Bilezikian, J. P., A. M. Spiegel, E. M. Brown, and G. D. Aurbach. 1977. Identification and persistence of beta-adrenergic receptors during maturation of the rat reticulocyte. Mol. Pharmacol. 13: 775-785.

33. Williams, R. W., C. E. Guthrow, and R. J. Lefkowitz. 1978. Beta-adrenergic and prostaglandin receptors in lymphocytes from hyperthyroid patients. Clin. Res. 26: 315A. (Abstr.)

34. Virenda, S. K., and S. P. Banerjee. 1978. $\beta$-Adrenergic receptors in rat skeletal muscle: Effects of thyroidectomy. Biochim. Biophys. Acta. 539: 538-542.

35. Gardner, J. D., H. L. Klaeveman, J. P. Bilezikian, and G. D. Aurbach. 1973. Effect of $\beta$-adrenergic catecholamines upon sodium transport in the turkey erythrocyte. J. Biol. Chem. 248: 5590-5596.
36. Banerjee, S. P., and L. S. Lung. 1977. $\beta$-Adrenergic receptors in rat heart: Effects of thyroidectomy. Eur. J. Pharmacol. 43: 207-208.

37. Smith, R. M., W. S. Osbornewhile, and R. A. King. 1978. Changes in the sarcolemma of the hypothyroid heart. Biochem. Biophys. Res. Commun. 80: 715-721.

38. Krishna, G., A. Hynie, and B. B. Brodie. 1968. Effects of thyroid hormones on adenyl cyclase in adipose tissues and on free fatty acid mobilization. Proc. Natl. Acad. Sci. U. S. A. 59: 884-889.

39. Levey, G. S., C. L. Skelton, and S. E. Epstein. 1969. Decreased myocardial adenyl cyclase activity in hypothyroidism. J. Clin. Invest. 48: 2244-2250.

40. Rosenqvist, U. 1972. Noradrenaline-induced lipolysis in subcutaneous adipose tissue from hypothyroid subjects. Acta Med. Scand. 192: 361-369.

41. Williams, A. F. 1972. DNA synthesis in purified populations of avian erythroid cells. J. Cell. Sci. 10: 27-43.

42. Sturkie, P. D., and P. Griminger. 1976. Blood: Physical characteristics, formed elements, hemoglobin, and coagulation. In Avian Physiology. P. D. Sturkie, editor. Springer-Verlag New York, Inc. New York. 53-75. 